\title{
Pilot Study of the SCFA Headspace Analysis of Streptococcus mutans Metabolites in Media with and without Polyols
}

\author{
Goudarzi, S. Habibi ${ }^{1}$, Kabat, B. ${ }^{2}$, Cannon, M. ${ }^{*}$, Gashkoff, M. ${ }^{2}$, and Zurek, R. ${ }^{2}$ \\ 1 Northwestern University, Chicago, IL; markcannon@northwestern.edu \\ 2 Ann and Robert Lurie Children's Hospital, Chicago, IL; bjkabat@gmail.com \\ * Correspondence: drmarkcannon@outlook.com;
}

\begin{abstract}
This pilot study of Streptococcus mutans ATCC 35668 grown in media with and without polyols (erythritol) measured the resultant metabolites, including the short chain fatty acids by using head space analysis. Brain Heart Infusion Broth (BHI2 or BHI10) supplemented with $2 \%$ or $10 \%$ sucrose containing no polyols or either erythritol or xylitol and Streptococcus mutans (ATCC 35668) was grown aerobically. After 48 hours of growth the supernatant were harvested and centrifuged to pellet bacteria. Supernatants were removed from bacterial pellets then submitted for Short Chain Fatty Acid (SCFA) analysis with an Agilent Technologies (Santa Clara, CA 95051) system configured from three components, a 5973 mass selective detector, a $6890 \mathrm{~N}$ gas chromatographer, and a 7697A headspace sampler. Streptococcus mutans growing in Brain Heart Infusion Broth (BHI2 or BHI10) supplemented with $2 \%$ or $10 \%$ sucrose but containing no polyols produced the following short chain fatty acids: methyl isovalerate, acetic acid, propionic acid, butanoic acid, pentanoic acid, ethyl butaric acid, 4-methylvaleric acid, hexanoic acid. When the Brain Heart Infusion Broth (BHI2 or BHI10) supplemented with $2 \%$ or $10 \%$ sucrose containing erythritol was used as media for this Streptococcus mutans strain, the following were produced: ethanol, acetoin, and acetic acid. Our results would suggest that constituents of the media may affect the bacterial metabolite production.
\end{abstract}

Keywords: prebiotics; polyols; short chain fatty acids, Headspace Analysis

\section{Introduction}

Very little research has actually been focused on the SCFA production of one of mankind's most prevalent pathogens, Streptococcus mutans. Streptococcus mutans is a key dental pathogen, long associated with one of the most common diseases of humankind. ${ }^{1}$ The incidence of dental caries in over $98 \%$ of the 65 years and above population demonstrates the universality of this disease. ${ }^{2}$ However, dental caries is totally preventable, being the result of a dysbiosis of the oral cavity, with both the increased presence of oral pathogens and the decreased level of protective commensals, particularly the nitrate reducing commensals. ${ }^{3}$ The oral microbiome shifts significantly over the different time periods of child development and in response to the diet. ${ }^{4}$ Unfortunately, the oral microbiome has had the same response as the Gut microbiome to the massive dietary shifts; the Agricultural, Industrial, and more currently, the Fast Food revolutions. ${ }^{5}$ That is, there has been a relative decrease in diversity coinciding with an increase not only in the number of pathogens, but also their pathogenicity. ${ }^{6}$

Efforts to reduce the levels of Streptococcus mutans in infants and children with xylitol and preventing dental caries have been successful. ${ }^{7 \text { and } 8}$ However, other bacterial and fungal organisms have now been closely identified with the development of dental caries. ${ }^{9}$ Scardovia wiggsiae is a Bacillus bacteria found extensively associated with Severe-Early Childhood Caries. ${ }^{10}$ Scardovia wiggsiae and Slackia exigua have been reported to be involved in the early caries development. ${ }^{11}$ Candida albicans, a fungal organism, helps with the biofilm production by increasing the extracellular polysaccharide matrix which protects Streptococcus mutans from anti-microbials and commensals 
such as Streptococcus oralis. ${ }^{12}$ Lactobacilli inhibit the colonization of Candida albicans, hence decreasing the polysaccharide matrix, exposing the Streptococcus mutans to the bactericins or hydrogen peroxide of its natural competitors, other Streptococcus species. ${ }^{13}$ Streptococcus oralis produces hydrogen peroxide that inhibits the anaerobic Streptococcus mutans growth. ${ }^{14}$ and 15 Indeed, Probiora probiotic, a commercially available probiotic product, contains Streptococcus oralis, uberis and rattus, and claims to inhibit several key dental pathogens. ${ }^{16-19}$ Probiotics have been reported to be an important adjunct in preventive dental care. ${ }^{20-22}$ Xylitol has been studied for its effect on the lactobacillus bacteria, a genus that consists of many probiotics, and it has been reported that xylitol does not significantly inhibit the Lactobacilli.

Polyols, sugar alcohols, have a distinct effect upon the microbiome and have long been utilized in oral medicine to reduce pathogen populations and also are referred to as prebiotics. Significant research studies have long demonstrated the effectiveness of polyol ingestion for the prevention of dental caries and now also for periodontal pathology 23 and 24 . A significant portion of the effectiveness is reportedly due to the polyol effect on the pathogenic microbiome ${ }^{25}$. Pathogens are more susceptible to the inhibitory effect of xylitol than the commensal bacteria. Studies of xylitol demonstrated little effect on probiotic bacteria, and long clinical studies demonstrate the biofilm effects are long term, and even are transmissible from mother to child 26 and 27 . Polyols safely inhibit the growth and biofilm production of oral pathogens that also have a significant effect systemically, such as, Streptococcus mutans causing hemorrhagic stroke. ${ }^{28}$ In addition, polyols shift the metabolites (acetate, lactate and propionate) produced by the oral microbiome. ${ }^{29}$ Carious dentin contains both acetate and propionate, produced by cariogenic bacteria prompting the research into the propionic acid production by Streptococcus mutans. ${ }^{30}$ Polyols have been reported to shift the production of the organic acids of the oral microbiome in the young patient population creating a long term benefit. ${ }^{31}$

\section{Materials and Methods}

Brain Heart Infusion Broth (BHI2 or BHI10) supplemented with $2 \%$ or $10 \%$ sucrose containing no polyols or either erythritol or xylitol at various concentrations was used for this study. Streptococcus mutans (ATCC 35668) was grown aerobically. After 48 hours of growth the supernatant were harvested and centrifuged to pellet bacteria. Supernatants were removed from bacterial pellets, filtered through 0.22 micron filters and stored in sterile cryovials until submitted for Short Chain Fatty Acid (SCFA) analysis at the IMSERC Mass Spectrometry Center (Northwestern University).

The instrument utilized was an Agilent Technologies (Santa Clara, CA 95051) system configured from three components, a 5973 mass selective detector, a 6890N gas chromatographer, and a 7697A headspace sampler. Mixture components separation was achieved by using a FFAP column (Agilent J\&W DB-FFAP; is a nitroterephthalic-acid-modified PEG) and a 10 minute temperature gradient (initial temperature at 50o C, hold for 1 minute, and ramp to 240o C in 6 minutes, and hold for 3 minutes, to give a total run time of 10 minutes). The standards of each of the SCFA samples were made in water and linearity established before test samples were committed to analysis. The linearity of the test samples was also demonstrated before the data was accepted. The SCFA test samples were analyzed as submitted without need for any further processing. Headspace oven incubation times of 15 minutes were used for both test samples and standard solutions.

\section{Results}


Representative Data : Standard, Positive Control, Negative Control

\begin{tabular}{|c|c|c|c|}
\hline & $\begin{array}{c}\text { Acetic Acid } \\
\text { (m/z } 60 \text { Area cnts) }\end{array}$ & $\begin{array}{c}\text { Sample Volume } \\
\text { (uL) }\end{array}$ & $\begin{array}{c}\text { On column } \\
\text { (ng/uL) }\end{array}$ \\
\hline Basal Media Neg Control - 07112016 & 137694 & 10 & 1.05 \\
\hline CX-Sup-48hrs-Pos-Cont - 07112016 & 1786539 & 10 & 13.60 \\
\hline
\end{tabular}

Standard Solution: 5 SCFA, 3 Analogs

Tests Sample

CX-Sup-48hrs-Pos-Cont-07112016

Tests Sample

Basal-Media-Neg-Control-07112016

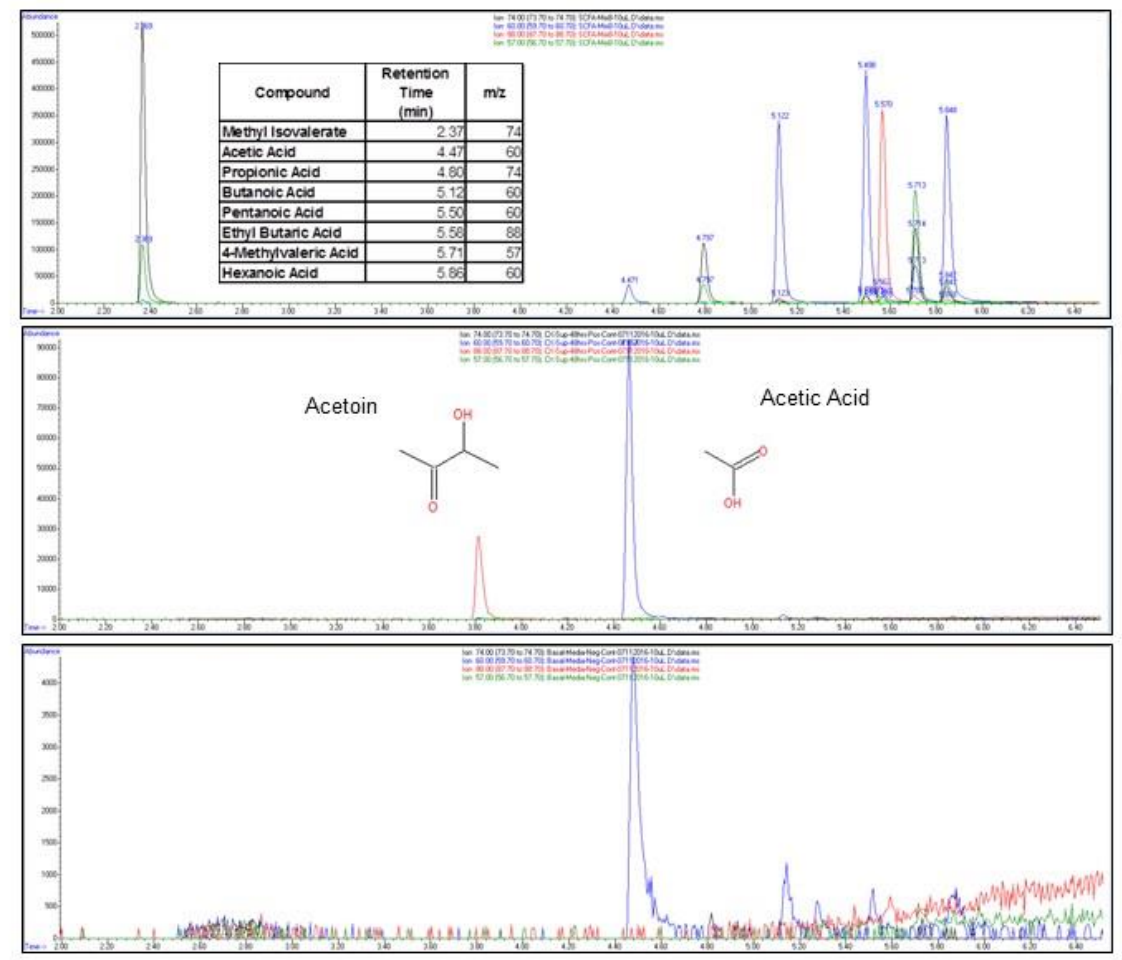

Figure 1. Headspace-GCMS representative chromatograms -- (a) Standard mix containing five short chain fatty acids and three analogs. Inset table shows retention time and $\mathrm{m} / \mathrm{z}$ of each component. (b) Positive control sample prepared by using CX-SUP-48hrs. (c) Negative control sample prepared by using Basal Media.

When the Brain Heart Infusion Broth (BHI2 or BHI10) was supplemented with 2\% or 10\% sucrose but containing no polyols was used to grow Strep Mutans, the following short chain fatty acids were produced: methyl isovalerate, acetic acid, propionic acid, butanoic acid, pentanoic acid, ethyl butaric acid, 4-methylvaleric acid, hexanoic acid. Note that this particular strain of Streptococcus mutans did not produce lactic acid. When the Brain Heart Infusion Broth (BHI2 or BHI10) supplemented with $2 \%$ or $10 \%$ sucrose containing erythritol was used as media for this Streptococcus mutans strain, the following were produced: ethanol, acetoin, and acetic acid. Note that propionic acid was not detected.

Sample BK-4: Erythritol-1.25mg 


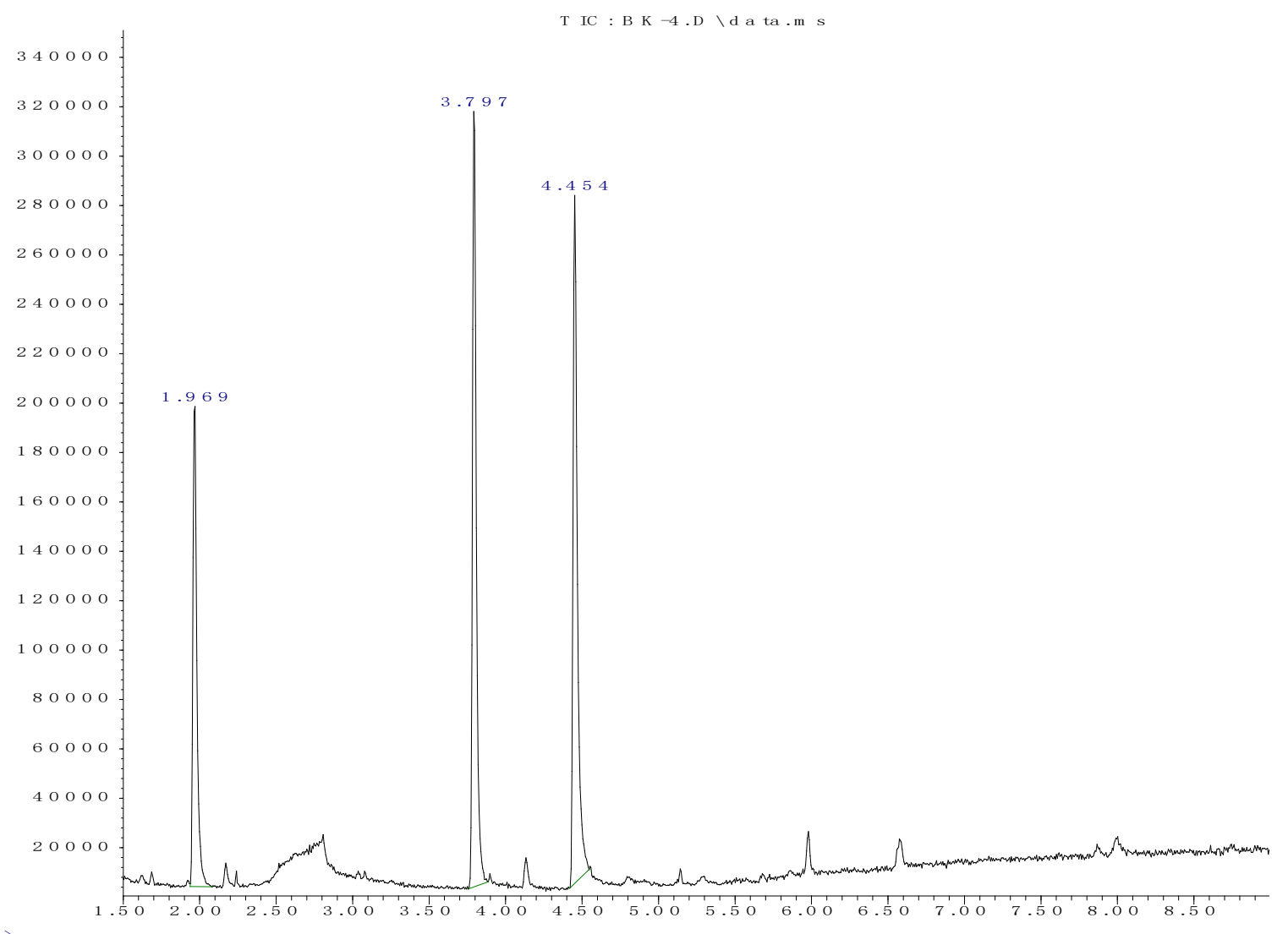

\begin{tabular}{|l|r|r|}
\hline \multicolumn{1}{|c|}{ Compound } & \multicolumn{1}{|c|}{$\begin{array}{c}\text { Retention } \\
\text { Time } \\
\text { (min) }\end{array}$} & m/z \\
\hline Methyl Isovalerate & 2.4 & 74 \\
\hline Acetic Acid & 4.5 & 60 \\
\hline Propionic Acid & 4.8 & 74 \\
\hline Butanoic Acid & 5.1 & 60 \\
\hline Pentanoic Acid & 5.5 & 60 \\
\hline Ethyl Butaric Acid & 5.6 & 88 \\
\hline 4-Methylvaleric Acid & 5.7 & 57 \\
\hline Hexanoic Acid & 5.9 & 60 \\
\hline & & \\
\hline Ethanol & 2.0 & 45 \\
\hline Acetoin & 3.8 & 45 \\
\hline
\end{tabular}

Figure 2. BK-4 test sample headspace-GCMS total ion chromatogram showing the presence of ethanol at retention time 2.0 minutes, Acetoin at retention time 3.8 minutes, and Acetic Acid at retention time 4.5 minutes. (Retention time and $\mathrm{m} / \mathrm{z}$ table is provided as a guide). 


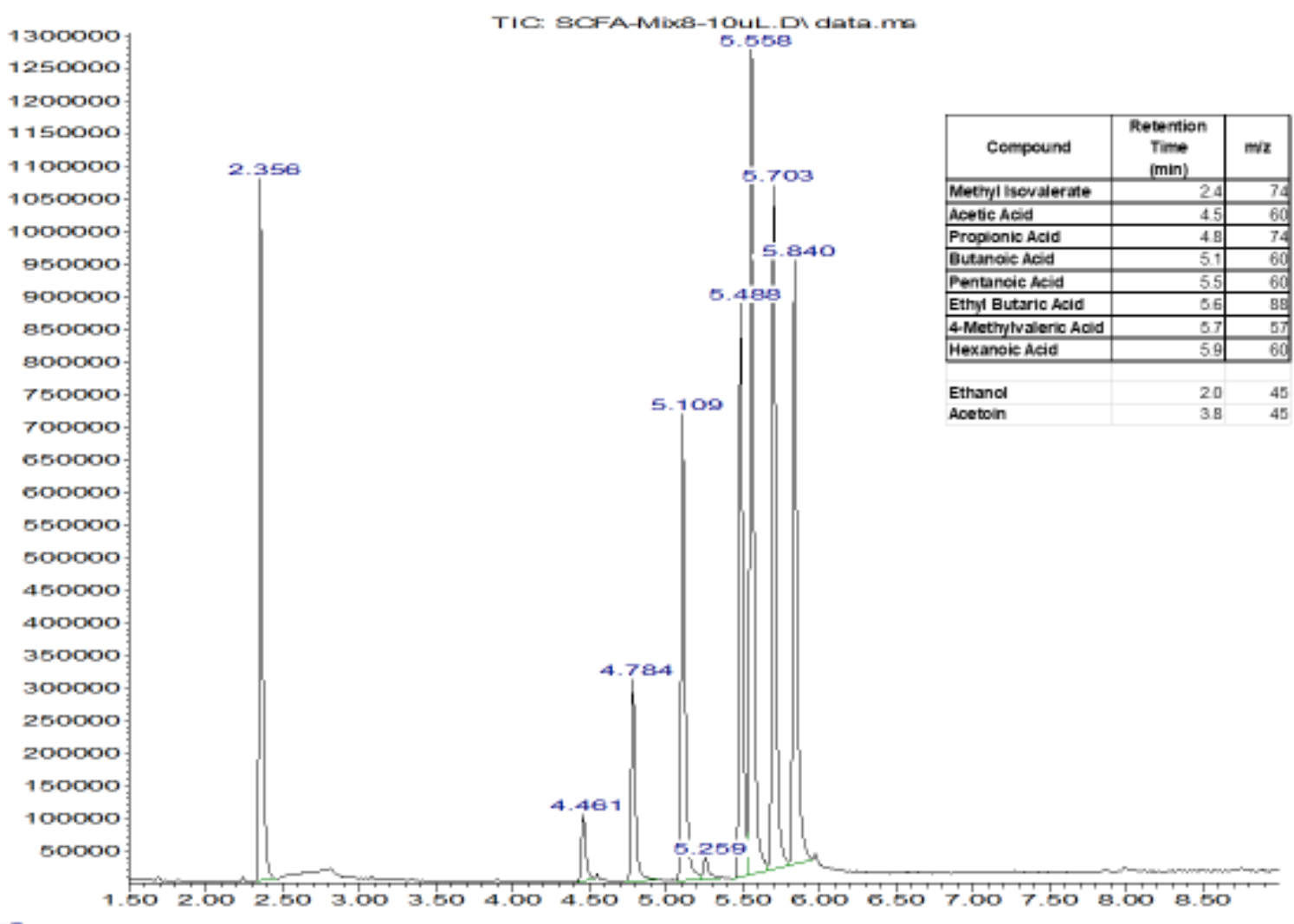

Figure 3. Headspace-GCMS total ion chromatogram of standard mix (5 SCFA and 3 analogs) from a $52 \mathrm{ng}$ injection of each component on column. Inset table provided as a guide showing the retention times and identifying $\mathrm{m} / \mathrm{z}$ value for each component. 


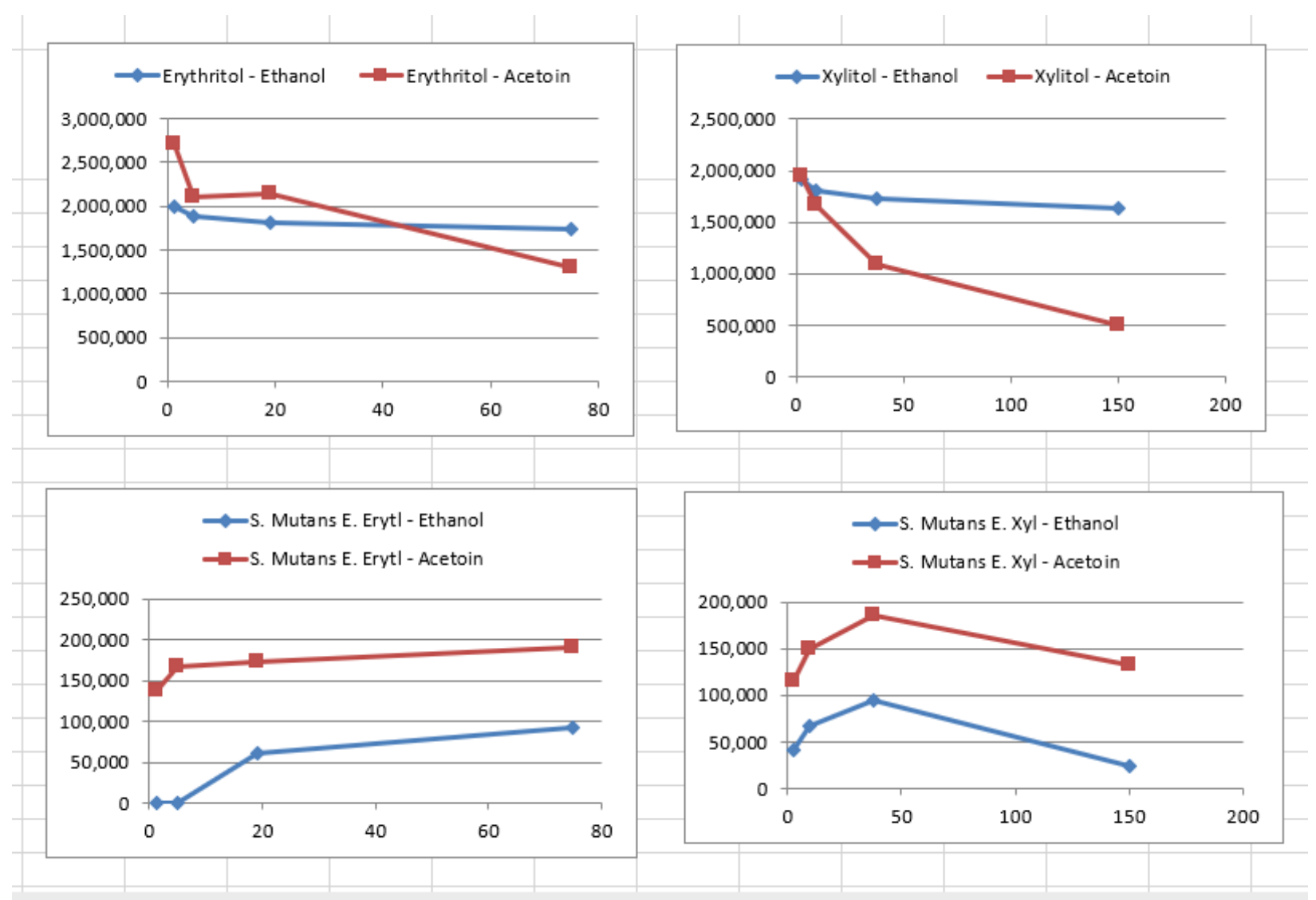

Figure 4. Evidence of modification of microbiome metabolites with polyols -- Graphs showing signal intensities for ethanol (a) and acetoin (b) trends relative to the amount of Erythritol and Xylitol (x axis, in $\mathrm{mg}$ ) added to the growth media without the presence of $\mathrm{S}$. mutans. In the presence of $\mathrm{S}$. mutans and Erythritol (c) and Xylitol (d), ethanol and acetoin signal intensities are significantly affected. 
Table 1: Microbiome metabolites modification with polyols results table. Samples 1 through 3 show the background intensities of acetic acid, ethanol, and acetoin in control media with $10 \%$ sucrose, S. Mutans negative control, and S. Mutans positive control, respectively. Samples 4 through 7 have various amounts of erythritol and samples 8 through 11 have various amounts of xylitol added to the growth media. Samples 12 through 15 have both erythritol and S. Mutans added to the growth media. Samples 16 through 19 have xylitol and S. Mutans added to the growth media.

\begin{tabular}{|c|c|c|c|c|c|c|c|c|}
\hline \multirow[b]{2}{*}{$\begin{array}{c}\text { Sample } \\
\text { Number }\end{array}$} & \multirow[b]{2}{*}{ File Name } & \multirow[b]{2}{*}{ Sample ID } & \multirow{2}{*}{\multicolumn{2}{|c|}{$\begin{array}{c}\text { Acetic Acid } \\
\text { (m/z } 60 \text { Area cnts) }\end{array}$}} & \multirow[b]{2}{*}{$\begin{array}{c}\text { Sample } \\
\text { Volume (uL) }\end{array}$} & \multirow[b]{2}{*}{$\begin{array}{c}\text { Conc. } \\
\text { (ng/uL) }\end{array}$} & \multicolumn{2}{|c|}{$\begin{array}{l}\text { No Quantitation; } \\
\text { Area counts only }\end{array}$} \\
\hline & & & & & & & $\begin{array}{c}\text { Ethanol } \\
\text { (Ret. Time 1.97 } \\
\mathrm{min}, \mathrm{m} / \mathbf{z} 45 \text { ) }\end{array}$ & $\begin{array}{c}\text { Acetoin } \\
\text { (Ret. Time } \\
\text { 3.80 } \mathrm{min}, \mathrm{m} / \mathrm{z} \text { 45) }\end{array}$ \\
\hline 0 & Blank-1 & Air Blank & & 0 & 0 & 0 & 0 & 0 \\
\hline 1 & BK-1 & + control, $10 \%$ sucrose & & 117677 & 10 & 0.87 & 0 & 0 \\
\hline 2 & BK-2 & S. Mutans control (-) media & & 103519 & 10 & 0.76 & 0 & 0 \\
\hline 3 & BK-3 & S. Mutans E. control (+) Opolyol & & 134802 & 10 & 1.00 & 0 & 0 \\
\hline 0 & Blank-2 & Air Blank & & 0 & 0 & 0 & 0 & 0 \\
\hline 4 & BK-4 & Erythritol-1.25mg & 1.25 & 1608577 & 10 & 11.88 & 2001284 & 2703626 \\
\hline 5 & BK-5 & Erythritol-5mg & 5 & 1623546 & 10 & 11.99 & 1880777 & 2097052 \\
\hline 6 & BK-6 & Erythritol-19mg & 19 & 1544335 & 10 & 11.40 & 1804859 & 2131294 \\
\hline 7 & BK-7 & Erythritol-75mg & 75 & 1434725 & 10 & 10.59 & 1734627 & 1291860 \\
\hline 0 & Blank-3 & Air Blank & & 0 & 0 & 0 & 0 & 0 \\
\hline 8 & BK-8 & Xylitol-2.3mg & 2.3 & 1716499 & 10 & 12.67 & 1914897 & 1949298 \\
\hline 9 & BK-9 & Xylitol-9.5mg & 9.5 & 1582268 & 10 & 11.68 & 1798844 & 1659580 \\
\hline 10 & BK-10 & Xylitol-37.5mg & 37.5 & 1533237 & 10 & 11.32 & 1728392 & 1087418 \\
\hline 11 & BK-11 & Xylitol-150mg & 150 & 1251579 & 10 & 9.24 & 1627455 & 492000 \\
\hline 0 & Blank-4 & Air Blank & & 0 & 0 & 0 & 0 & 0 \\
\hline 12 & BK-12 & S. Mutans E. Erytl-1.25mg & 1.25 & 148546 & 10 & 1.10 & 0 & 137743 \\
\hline 13 & BK-13 & S. Mutans E. Erytl-5mg & 5 & 117115 & 10 & 0.86 & 0 & 167627 \\
\hline 14 & BK-14 & S. Mutans E. Erytl-19mg & 19 & 207706 & 10 & 1.53 & 60863 & 172709 \\
\hline 15 & BK-15 & S. Mutans E. Erytl-75mg & 75 & 178909 & 10 & 1.32 & 92606 & 190880 \\
\hline 0 & Blank-5 & Air Blank & & 0 & 0 & 0 & 0 & 0 \\
\hline 16 & BK-16 & S. Mutans E. Xyl-2.5mg & 2.5 & 165235 & 10 & 1.22 & 41527 & 114900 \\
\hline 17 & BK-17 & S. Mutans E. Xyl-9.5mg & 9.5 & 181382 & 10 & 1.34 & 67282 & 149012 \\
\hline 18 & BK-18 & S. Mutans E. Xyl- $37.5 \mathrm{mg}$ & 37.5 & 144051 & 10 & 1.06 & 94859 & 184817 \\
\hline 19 & BK-19 & S. Mutans E. Xyl-150mg & 150 & 198161 & 10 & 1.46 & 24503 & 131880 \\
\hline
\end{tabular}

\section{Discussion}

Modification of the microbiome metabolites with polyols, or possibly the diet in general, has greater effects than previously appreciated. Research into epigenetic effects, the response of the genome to environmental factors, including the influence of SCFAs has greatly increased. Therefore, significant study of the microbiome, the microbiome effect epigenetically, and the modification of the microbiome via polyols, deserves intense interest. In this pilot study, we analyzed the effects of polyols on only one pathogen, but the effect was demonstrative.

In humans, the gut microbiota plays an important role in many functions, such as modulation of the immune system, production of vitamins and amino acids, the detoxification of harmful chemicals, and the breakdown of dietary fiber into short chain fatty acids. In this study, we examined the role Streptococcus mutans may play in the production of short chain fatty acids in vitro, and how the changing environment (media with polyol added) has an impact on what types of short chain fatty acids are produced. When a strain of Streptococcus mutans was grown with sucrose, it produced different SCFAs than when grown with the polyol erythritol. Most notably, when grown with erythritol, this strain no longer produced propionic acid.

By shifting production away from propionic acid, the erythritol environment allows other SCFAs to dominate amongst the metabolites of Streptococcus mutans. Propionic infusions into adult 
rat cerebral ventricles produces behaviors associated with autism, (ASD) ${ }^{32}$ and produces reversible repetitive dystonic behaviors, hyperactivity, turning behavior, retropulsion, caudate spiking, and the progressive development of limbic kindled seizures, coupled with neuroinflammatory, metabolic and epigenetic changes suggesting that it has central effects ${ }^{33}$ and 34 . Derrick et al also administered propionic acid subcutaneously and intra peritoneal finding very similar results. ${ }^{35}$ and 36 Exposure of human lymphoblastoid cell lines to propionic acid elicited an atypical immunologic response. 37 and 38 On the other hand, propionic acid also has positive health effects with adults, such as anti-obesity, anti-inflammatory, and cholesterol lowering effects ${ }^{39}$. Calcium propionate has been utilized as a food preservative although the use appears to be decreasing as a large fast food restaurant chain recently announced discontinuing calcium propionate due to concerns over behavioral changes in children consuming calcium propionate preserved bread. ${ }^{40}$

Additional laboratory study is required to test other species besides Streptococcus mutans, specifically the propionic producing Clostridium histolyticum and bolteae. By adding polyols to the diet, we could potentially shift the SCFA production to decrease the amount of propionic acid produced. Various low refined carbohydrate diets may help with ASD by reducing the substrates needed for SCFA production, and the supplementation of foods high in complex fibers may exert a therapeutic response in children by preferentially increasing the production of another SCFA, butyrate, over the production of propionic acid ${ }^{41}$.

Short-chain fatty acids (SCFA) formed by microbial fermentation have an important effect on colonic health 42 and 43 . Butyrate particularly has an important role in the metabolism and normal development of colonic epithelial cells and has been demonstrated to be protective against cancer and ulcerative colitis ${ }^{44}$. Butyrate is considered to be a preferred energy source for colonic epithelial cells and plays an important role in maintaining colonic health in humans. In a study of the colonic bacteria by Barcenilla et al, fifty percent of the butyrate-producing isolates were net acetate consumers during growth, but only $1 \%$ of the 239 non-butyrate-producing isolates consumed acetate 45. Acetate would then seem to be an important precursor to butyrate production, a health benefit. However, too much acetate from bacterial production may promote metabolic syndrome ${ }^{46}$. Butyrate is essential for colonic health and has been shown to inhibit growth and induce apoptosis of colonic tumor cell lines ${ }^{47}$, and could therefore be used for cancer treatment. An altered gut microbiome has been shown to increase SCFA production of acetic acid which will activate the parasympathetic nervous system, increase glucose-stimulated insulin secretion, increase ghrelin secretion (the hunger hormone), and contribute to hyperphagia and obesity ${ }^{48}$. Therefore, acetic acid could be targeted by therapeutics to reduce obesity.

The data already accumulated in regards to the therapeutic use of polyols encourages additional research into their microbiome metabolite shifts. The shift away from production of propionate could be of extreme importance, as research has clearly implicated propionate as a potential potentiator of A.S.D. symptoms 49 and 50 . The use of polyols to treat dental diseases has proven the safety of both xylitol and erythritol, not even considering the other positive side-effects such as the lowering of blood pressure, triglycerides and L.D.L.s ${ }^{51}$. The oral microbiome of patients diagnosed with autism spectrum disorder also demonstrate an altered oral microbiome, with an increase in pathogens, such as, Streptococcus, that are susceptible to polyol therapy. ${ }^{52}$ Knowing all this should reduce hesitancy in initiating animal then controlled human studies on microbiome shifts, metabolites shifting, and behavioral expressions using polyols.

\section{Conclusions}

Constituents of media, such as supplemental polyols, effect the bacterial metabolite production of Streptococcus mutans in vitro. Additional laboratory study is in progress testing other species, specifically the propionic producing genus Clostridia, specifically Clostridium bolteae and Clostridium histolyticum for the SCFA metabolite production, and the shift in SCFA production with the addition of polyols. 
Acknowledgments: We are grateful for the support of the Goodlife Childrens Charities in providing the guidance and advice of Dr. Derrick MacFabe

Conflicts of Interest: The authors declare no conflict of interest.

\section{References}

1. Clarke J. K., On the bacterial factor in the etiology of dental caries. Brit J Exp Pathol 5:141-147. 1924

2. Loesche W. J., Role of Streptococcus mutans in human dental decay. Microbiol Rev 50:353-380. 1986

3. Senthil Eagappan, A. R., Rao, V. A., Sujatha, S., Senthil, D., Sathiyajeeva, J., \& Rajaraman, G. (2016). Evaluation of salivary nitric oxide level in children with early childhood caries. Dental research journal, 13(4), 338-341.

4. Lemos, J. A., Palmer, S. R., Zeng, L., Wen, Z. T., Kajfasz, J. K., Freires, I. A., ... Brady, L. J. (2019). The Biology of Streptococcus mutans. Microbiology spectrum, 7(1), 10.1128/microbiolspec.GPP3-0051-2018. doi:10.1128/microbiolspec.GPP3-0051-20.

5. Warinner, C., Speller, C., Collins, M. J., \& Lewis, C. M., Jr (2015). Ancient human microbiomes. Journal of human evolution, 79, 125-136. doi:10.1016/j.jhevol.2014.10.016

6. Bae J. M. (2018). Interpretation of the hygiene and microflora hypothesis for allergic diseases through epigenetic epidemiology. Epidemiology and health, 40, e2018006. doi:10.4178/epih.e2018006

7. Mäkinen, K. K., Järvinen, K. L., Anttila, C. H., Luntamo, L. M. and Vahlberg, T. (2013), Topical xylitol administration by parents for the promotion of oral health in infants: a caries prevention experiment at a Finnish Public Health Centre. Int Dent J, 63: 210-224.

8. Milgrom P, Ly KA, Tut OK, et al. Xylitol pediatric topical oral syrup to prevent dental caries: a double-blind randomized clinical trial of efficacy. Arch Pediatr Adolesc Med. 2009;163(7):601-607. doi:10.1001/archpediatrics.2009.77

9. Kuramitsu H. K., Wang B. Y., The whole is greater than the sum of its parts: dental plaque bacterial interactions can affect the virulence properties of cariogenic Streptococcus mutans. Am J Dent. 2011 Jun;24(3):153-4.

10. Kressirer, C. A., Smith, D. J., King, W. F., Dobeck, J. M., Starr, J. R., \& Tanner, A. (2017). Scardovia wiggsiae and its potential role as a caries pathogen. Journal of oral biosciences, 59(3), $135-141$. doi:10.1016/j.job.2017.05.002

11. Tanner, A. C., Kent, R. L., Jr, Holgerson, P. L., Hughes, C. V., Loo, C. Y., Kanasi, E., ... Johansson, I. (2011). Microbiota of severe early childhood caries before and after therapy. Journal of dental research, 90(11), 1298-1305. doi:10.1177/0022034511421201

12. Xiao, J., Huang, X., Alkhers, N., Alzamil, H., Alzoubi, S., Wu, T. T., ... Koo, H. (2018). Candida albicans and Early Childhood Caries: A Systematic Review and Meta-Analysis. Caries research, 52(1-2), 102-112. doi:10.1159/000481833

13. Matsubara, V.H., Wang, Y., Bandara, H.M.H.N. et al. Probiotic lactobacilli inhibit early stages of Candida albicans biofilm development by reducing their growth, cell adhesion, and filamentation. Appl Microbiol Biotechnol (2016) 100: 6415.

14. Bidossi, A., De Grandi, R., Toscano, M., Bottagisio, M., De Vecchi, E., Gelardi, M., \& Drago, L. (2018). Probiotics Streptococcus salivarius 24SMB and Streptococcus oralis 89a interfere with biofilm formation of pathogens of the upper respiratory tract. BMC infectious diseases, 18(1), 653. doi:10.1186/s12879-018-35769

15. Hillman J. D., Socransky S.S., Shivers M. (1985) The relationships between streptococcal species and periodontopathic bacteria in human dental plaque. Arch Oral Biol 30: 791-795

16. Hedayati-Hajikand, T., Lundberg, U., Eldh, C., \& Twetman, S. (2015). Effect of probiotic chewing tablets on early childhood caries--a randomized controlled trial. BMC oral health, 15(1), 112. doi:10.1186/s12903-0150096-5

17. Hillman J. D, Socransky S. S., The theory and application of bacterial interference to oral diseases. In New Biotechnology in Oral Research. Ed. Myers HM (Basel: S Karger) 1989; 1-17.

18. Zahradnik R. T., Magnusson I., Walker C., Mcdonnell E., Hillman C.H., Hillman J. D. Preliminary assessment of safety and effectiveness in humans of ProBiora3, a probiotic mouthwash. J Applied Micro 2009; 107:682-690.

19. Hillman J.D. , McDonnell E., Hillman C.H., Zahradnik R.T., Soni M.G., Safety assessment of ProBiora3, a probiotic mouthwash; subchronic toxicity study in rats. Int'1 J Toxicology 2009; 28:357-367. 
20. Cannon M. A Review of Probiotic Therapy in Preventive Dental Practice, Probiotics and Anti-microbial Proteins, Vol 3, Num 2, July 2011.

21. Cannon M., Trent B., Vorachek A., Kramer S., Esterly R., Effectiveness of CRT at measuring the salivary level of bacteria in caries prone children with probiotic therapy. J Clin Pediatr Dent. 2013 Fall;38(1):55-60.

22. Cannon M., Clinical Application of Probiotic Therapy, Inside Dentistry, 2011; June, 112-113

23. Janakiram C., Deepan Kumar C. V., Joseph J., Xylitol in preventing dental caries: A systematic review and meta-analyses. J Nat Sci Biol Med. 2017 Jan-Jun; 8(1): 16-21.

24. Park E., Sam Na H., Min Kim S., Wallet S., Cha S., Chung J. Xylitol, an Anticaries Agent, Exhibits Potent Inhibition of Inflammatory Responses in Human THP-1-Derived Macrophages Infected With Porphyromonas gingivalis. J Periodontol. 2014 Jun; 85(6): e212-e223.

25. Nayak P. A., Nayak U. A., Khandelwal V. The effect of xylitol on dental caries and oral flora. Clinical, Cosmetic and Investigational Dentistry. 2014;6:89-94. doi:10.2147/CCIDE.S55761.

26. Söderling E., Isokangas P., Pienihäkkinen K., Tenovuo J. Influence of maternal xylitol consumption on acquisition of mutans streptococci by infants. J Dent Res. 2000 Mar;79(3):882-7.

27. Falony G., Honkala S., Runnel R., Olak J., Nõmmela R., Russak S., Saag M., Mäkinen P.L., Mäkinen K., Vahlberg T., Honkala E. Long-Term Effect of Erythritol on Dental Caries Development during Childhood: A Posttreatment Survival Analysis. Caries Res. 2016;50(6):579-588. doi: 10.1159/000450762. Epub 2016 Nov 3.

28. Mansour, T. R., Alam, Y., Dahbour, L., Alnemari, A., Jumaa, M., \& Schroeder, J. L. (2017). Streptococcus Mutans: A Potential Risk Factor in Recurrent Hemorrhagic Stroke. Cureus, 9(5), e1264. doi:10.7759/cureus.1264

29. Runnel R., Mäkinen K.K., Honkala S., Olak J., Mäkinen P.L., Nõmmela R., Vahlberg T., Honkala E., Saag M. Effect of three-year consumption of erythritol, xylitol and sorbitol candies on various plaque and salivary caries-related variables. J Dent. 2013 Dec;41(12):1236-44. doi: 10.1016/j.jdent.2013.09.007. Epub 2013 Oct 3 .

30. Hojo S., Komatsu M., Okuda R., Takahashi N., Yamada T. Acid profiles and pH of carious dentin in active and arrested lesions. J Dent Res. 1994 Dec;73(12):1853-7. Caries Res. 2016;50(6):579-588. doi: 10.1159/000450762. Epub 2016 Nov 3.

31. Falony G1, Honkala S, Runnel R, Olak J, Nõmmela R, Russak S, Saag M, Mäkinen PL, Mäkinen K, Vahlberg T, Honkala E. Long-Term Effect of Erythritol on Dental Caries Development during Childhood: A Posttreatment Survival Analysis. Caries Res. 2016;50(6):579-588. doi: 10.1159/000450762. Epub 2016 Nov 3.

32. MacFabe D. F. , Cain D. P. , Rodriguez-Capote K. et al. Neurobiological effects of intraventricular propionic acid in rats: possible role of short chain fatty acids on the pathogenesis and characteristics of autism spectrum disorders. Behav Brain Res. 2007;176(1):149-69.

33. Shultz S. R., MacFabe D. F. , Ossenkopp K. P. et al. Intracerebroventricular injection of propionic acid, an enteric bacterial metabolic end-product, impairs social behavior in the rat: implications for an animal model of autism. Neuropharmacology. 2008;54(6):901-11.

34. Shultz S. R. , Macfabe D. F. , Martin S et al. Intracerebroventricular injections of the enteric bacterial metabolic product propionic acid impair cognition and sensorimotor ability in the Long-Evans rat: further development of a rodent model of autism. Behav Brain Res. 2009;200(1):33-41.

35. Foley K.A., Kavaliers M., MacFabe D.F., Ossenkopp K.P. Systemic treatment with the enteric bacterial metabolic product propionic acid results in reduction of social behavior in juvenile rats: Contribution to a rodent model of autism spectrum disorder. Dev Psychobiol. 2019 Jan 28. doi: 10.1002/dev.21825.

36. MacFabe D. F. , Cain N. E. , Boon F. et al. Effects of the enteric bacterial metabolic product propionic acid on object-directed behavior, social behavior, cognition, and neuroinflammation in adolescent rats: Relevance to autism spectrum disorder. Behav Brain Res. 2011;217(1):47-54.

37. Frye R. E., Nankova B., Bhattacharyya S., Rose S., Bennuri, S. C., MacFabe D. F. (2017). Modulation of Immunological Pathways in Autistic and Neurotypical Lymphoblastoid Cell Lines by the Enteric Microbiome Metabolite Propionic Acid. Frontiers in immunology, 8, 1670. doi:10.3389/fimmu.2017.01670

38. Rose et al. Butyrate enhances mitochondrial function during oxidative stress in cell lines from boys with autism. Translational Psychiatry. 2018;8:42.

39. Lin, H. V., Frassetto, A., Kowalik, E. J., Jr, Nawrocki, A. R., Lu, M. M., Kosinski, J. R., ... Marsh, D. J. (2012). Butyrate and propionate protect against diet-induced obesity and regulate gut hormones via free fatty acid receptor 3-independent mechanisms. PloS one, 7(4), e35240. doi:10.1371/journal.pone.0035240 
40. Dengate S., Ruben A., Controlled trial of cumulative behavioural effects of a common bread preservative. J Paediatr Child Health. 2002 Aug;38(4):373-6.

41. McNabney, S. M., Henagan, T. M. (2017). Short Chain Fatty Acids in the Colon and Peripheral Tissues: A Focus on Butyrate, Colon Cancer, Obesity and Insulin Resistance. Nutrients, 9(12), 1348. doi:10.3390/nu9121348

42. Cummings J. H., MacFarlane G. T.(1991) The colonic flora, fermentation and large bowel digestive function. in The large intestine: physiology, pathophysiology, and disease. eds Philips S. F., Pemberton J. H., Shorter R. G. (Raven Press, New York, N.Y), pp 51-91.

43. Szylit O., Andrieux C. (1993) Physiological and pathophysiological effects of carbohydrate fermentation. World Rev. Nutr. Diet. 74:88-122.

44. Hague A., Singh B., Paraskeva C. (1997) Butyrate acts as a survival factor for colonic epithelial cells: further fuel for the in vivo versus in vitro debate. Gastroenterology 112:1036-1040.

45. Barcenilla A. et al, Phylogenetic Relationships of Butyrate-Producing Bacteria from the Human Gut., Appl. Environ. Microbiol. April 2000 vol. 66 no. 4 1654-1661.

46. Chambers, E. S., Preston, T., Frost, G., \& Morrison, D. J. (2018). Role of Gut Microbiota-Generated ShortChain Fatty Acids in Metabolic and Cardiovascular Health. Current nutrition reports, 7(4), 198-206. doi:10.1007/s13668-018-0248-8

47. Bultman S. J. (2014). Molecular pathways: gene-environment interactions regulating dietary fiber induction of proliferation and apoptosis via butyrate for cancer prevention. Clinical cancer research : an official journal of the American Association for Cancer Research, 20(4), 799-803. doi:10.1158/10780432.CCR-13-2483

48. Perry R. J. et al, Acetate mediates a microbiome-brain- $\beta$-cell axis to promote metabolic syndrome. Nature 534, 213-217 (09 June 2016)

49. Frye R.E., Rose S., Slattery J., MacFabe D.F. Gastrointestinal dysfunction in autism spectrum disorder: the role of the mitochondria and the enteric microbiome. Microbial Ecology in Health and Disease. 2015;26:10.3402/mehd.v26.27458. doi:10.3402/mehd.v26.27458.

50. Li Q., Han .Y, Dy A. B. C., Hagerman R. J. The Gut Microbiota and Autism Spectrum Disorders. Frontiers in Cellular Neuroscience. 2017;11:120. doi:10.3389/fncel.2017.00120.

51. Ur-Rehman S., Mushtaq Z., Zahoor T., Jamil A., Murtaza M.A. Xylitol: a review on bioproduction, application, health benefits, and related safety issues. Crit Rev Food Sci Nutr. 2015;55(11):1514-28. doi: 10.1080/10408398.2012.702288.

52. Qiao Y., Wu Y., Feng Y., Zhou Z., Chen L., Chen F. Alterations of oral microbiota distinguish children with autism spectrum disorders from healthy controls. Sci Rep. 2018; 8: 1597.

53. Published online 2018 Jan 25. doi: 10.1038/s41598-018-19982-y 